\title{
Endonasal endoscopic transsphenoidal resection of intrinsic third ventricular craniopharyngioma: surgical results
}

\author{
Jonathan A. Forbes, MD, ${ }^{1}$ Edgar G. Ordóñez-Rubiano, MD, ${ }^{1,2}$ Hilarie C. Tomasiewicz, MD, PhD, ${ }^{1}$ \\ Matei A. Banu, MD, ${ }^{3}$ lyan Younus, BS, ${ }^{4}$ Georgiana A. Dobri, MD, ${ }^{1,5,8}$ C. Douglas Phillips, MD, ${ }^{6}$ \\ Ashutosh Kacker, MD, ${ }^{7}$ Babacar Cisse, MD, PhD, ${ }^{1}$ Vijay K. Anand, MD, ${ }^{7}$ and \\ Theodore H. Schwartz, MD1,7,8
}

\begin{abstract}
${ }^{1}$ Department of Neurological Surgery, Weill Cornell Medical College, New York Presbyterian Hospital, New York, New York; 2Department of Neurological Surgery, Fundación Universitaria de Ciencias de la Salud (FUCS), Hospital de San José, Bogotá, Columbia; ${ }^{3}$ Department of Neurological Surgery, Columbia Medical College, New York Presbyterian Hospital, New York, New York; ${ }^{4}$ Weill Cornell School of Medicine, New York, New York; ${ }^{5}$ Department of Endocrinology, Weill Cornell Medical College, New York Presbyterian Hospital, New York, New York; ${ }^{6}$ Department of Radiology, Weill Cornell Medical College, New York Presbyterian Hospital, New York, New York; ' 7 Department of Otolaryngology, Weill Cornell Medical College, New York Presbyterian Hospital, New York, New York; and ${ }^{8}$ Department of Neuroscience, Weill Cornell Medical College, New York Presbyterian Hospital, New York, New York
\end{abstract}

OBJECTIVE Intrinsic third ventricular craniopharyngiomas (IVCs) have been reported by some authors to "pose the greatest surgical challenge" of all craniopharyngiomas (CPAs). A variety of open microsurgical approaches have historically been used for resection of these tumors. Despite increased utilization of the endoscopic endonasal approach (EEA) for resection of CPAs in recent years, many authors continue to recommend against use of the EEA for resection of IVCs. In this paper, the authors present the largest series to date utilizing the EEA to remove IVCs.

METHODS The authors reviewed a prospectively acquired database of the EEA for resection of IVCs over 14 years at Weill Cornell Medical College, NewYork-Presbyterian Hospital. Preoperative MR images were examined independently by two neurosurgeons and a neuroradiologist to identify IVCs. Pre- and postoperative endocrinological, ophthalmological, radiographic, and other morbidities were determined from retrospective chart review and volumetric radiographic analysis.

RESULTS Between January 2006 and August 2017, 10 patients (4 men, 6 women) ranging in age from 26 to 67 years old, underwent resection of an IVC utilizing the EEA. Preoperative endocrinopathy was present in $70 \%$ and visual deterioration in $60 \%$. Gross-total resection (GTR) was achieved in $9(90 \%)$ of 10 patients, with achievement of near-total $(98 \%)$ resection in the remaining patient. Pathology was papillary in $30 \%$. Closure incorporated a "gasket-seal" technique with nasoseptal flap coverage and either lumbar drainage (9 patients) or a ventricular drain (1 patient). Postoperatively, complete anterior and posterior pituitary insufficiency was present in $90 \%$ and $70 \%$ of patients, respectively. In 4 patients with normal vision prior to surgery, 3 had stable vision following tumor resection. One patient noted a new, incongruous, left inferior homonymous quadrantanopsia postoperatively. In the 6 patients who presented with compromised vision, 2 reported stable vision following surgery. Each of the remaining 4 patients noted significant improvement in vision after tumor resection, with complete restoration of normal vision in 1 patient. Aside from the single case (10\%) of visual deterioration referenced above, there were no instances of postoperative neurological decline. Postoperative CSF leakage occurred in 1 morbidly obese patient who required reoperation for revision of closure. After a mean follow-up of 46.8 months (range 4-131 months), tumor recurrence was observed in 2 patients (20\%), one of whom was treated with radiation and the other with chemotherapy. Both of these patients had previously undergone GTR of the IVC.

CONCLUSIONS The 10 patients described in this report represent the largest number of patients with IVC treated using

ABBREVIATIONS CPA = craniopharyngioma; EEA = endoscopic endonasal approach; GTR = gross-total resection; IVC = intrinsic third ventricular craniopharyngioma; NTR = near-total resection; STR = subtotal resection; WCMC = Weill Cornell Medical College; XRT = radiation therapy.

SUBMITTED January 24, 2018. ACCEPTED May 29, 2018.

INCLUDE WHEN CITING Published online November 16, 2018; DOI: 10.3171/2018.5.JNS18198. 


\begin{abstract}
EEA for resection to date. EEA for resection of IVC is a safe and efficacious operative strategy that should be considered a surgical option in the treatment of this challenging subset of tumors.

https://thejns.org/doi/abs/10.3171/2018.5.JNS18198
\end{abstract}

KEYWORDS intraventricular; third ventricle; craniopharyngioma; endonasal; minimally invasive; endoscopic; pituitary surgery

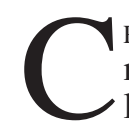
RANIOPHARYNGIOMAS (CPAs) are benign tumors of neuroepithelial derivation that originate from cellular rests associated with the primitive craniopharyngeal duct. ${ }^{29}$ They arise along the pituitary-hypothalamic axis and can extend to infiltrate the sellar region, suprasellar space, parasellar compartment, interpeduncular cistern, and/or third ventricle. Methods of operative intervention frequently considered include a variety of open, microsurgical techniques - including pterional, orbitozygomatic, bifrontal, extended bifrontal, supraorbital keyhole, and posterior petrosal approaches -in addition to transsphenoidal resection. ${ }^{1,28,29}$ In early series, transsphenoidal approaches were predominantly limited to intrasellar, infradiaphragmatic CPAs. ${ }^{32}$ In subsequent years, increased utilization of the transsphenoidal corridor for CPAs with suprasellar extension has been advocated. ${ }^{13,20}$ Currently, at many institutions, the endoscopic endonasal approach (EEA) is favored as the approach of choice for most craniopharyngiomas, as the literature has revealed higher rates of resection and decreased associated neurological morbidity. $3,4,7,8,13,14,17,19,22$ In their original report, Kassam et al. recommended against endonasal approaches for resection of type IV (intrinsic third ventricular) CPAs. ${ }^{13}$ Despite considerable evolution in surgical technology and operative techniques over the past decade, the perception that intrinsic third ventricular craniopharyngiomas (IVCs) are not amenable to endonasal resection remains widely prevalent today. ${ }^{6,13,25,28,31}$

IVCs have been reported by some authors to "pose the greatest surgical challenge" of all CPAs, especially when an associated cystic component is lacking. ${ }^{28}$ In previous large series, the subset of CPAs reported as "purely intraventricular" has ranged from $3 \%$ to $11 \%$ of all CPAs. ${ }^{33}$ From 2004 to the present, it has been the senior author's (T.H.S.) preference to resect all CPAs, including IVCs, using an endoscopic endonasal corridor. A report of the surgical outcomes and operative nuances associated with EEA for resection of IVCs is provided in this paper.

\section{Methods}

\section{Preoperative Assessment and Patient Selection}

Following IRB approval from Weill Cornell Medical College (WCMC), the authors reviewed a prospectively acquired database of patients who underwent endonasal endoscopic resection of CPAs compiled over a period of 11 years (2004-2017), performed by the senior authors (T.H.S. and V.K.A.).

Preoperative imaging was reviewed by the primary author (J.A.F.) in each case to evaluate tumor size and location in determining the potential for study inclusion. Confirmation of an IVC required concordant assessment from a dedicated neuroradiologist (C.D.P.) as well as the senior author. Using criteria described in previous reports, the CPA was retrospectively characterized as an IVC if the tumor was noted to solely occupy the confines of the third ventricle on axial, sagittal, and coronal preoperative imaging without overt evidence of penetration of the third ventricle floor or free extension into the suprasellar cistern, interpeduncular cistern, infundibulum, or sellar region. ${ }^{30,33}$ Consistent with the study by Pascual et al., special attention was given to location and integrity of the third ventricle floor on coronal images. 25 "Pseudointraventricular" tumors that arose inferior to the third ventricle floor and displaced the floor upward, were identified and excluded. Additionally, "secondarily intraventricular tumors" that arose inferior to the third ventricle floor and grew to invade the third ventricle secondarily were identified and excluded. In this analysis, tumors limited to the confines of the third ventricle (i.e., Kassam type IV tumors) that satisfied the Pascual criteria of "strictly intraventricular" and "infundibulotuberal" were denoted as IVCs and selected for study inclusion.

Prior to surgery, all patients were evaluated by an endocrinologist and subjected to routine endocrinological testing. Visual function was clinically assessed before surgery in all patients. In patients who reported visual symptoms, formal neuroophthalmological examination with Humphrey visual field assessment was obtained. The electronic medical records were retrospectively examined for additional relevant preoperative data (e.g., age, sex, history of previous surgeries, presenting symptoms, and neurological deficits). Tumor volume was estimated using measurements obtained from MRI in three dimensions divided by a factor of two: $(\mathrm{A} \times \mathrm{B} \times \mathrm{C}) / 2$.

\section{Surgical Technique}

At WCMC, the surgical team consists of an endoscopic skull base neurosurgeon (T.H.S.) and an otorhinolaryngologist (V.K.A. or A.K.). The technique has been described in detail in prior publications and is mentioned briefly below. ${ }^{5,19,27}$ Intraoperatively, a lumbar drain is placed and $0.25 \mathrm{ml}$ of $10 \%$ fluorescein (AK-Fluor, Akorn) is given intrathecally to help with visualization of intraoperative CSF leakage during tumor removal and again following closure. ${ }^{26}$ The middle turbinates are lateralized and a nasoseptal flap is harvested prior to posterior septectomy. Partial ethmoidectomies and a wide sphenoidotomy are performed. The lateral margin of bone removal spans from medial opticocarotid recess to medial opticocarotid recess. The bone that is removed is done so in a manner that facilitates subsequent implementation of the "gasketseal" closure at the end of the case. The dura is opened above and below the superior intercavernous sinus, which is coagulated and transected. The arachnoid is subsequent- 
ly opened sharply with microscissors, revealing the underlying chiasm, stalk, superior hypophyseal arteries, and tributaries. There is considerable variability of the superior hypophyseal arterial system, which joins with arterial branches from the contralateral side as well as additional branches from the posterior communicating artery to form a circuminfundibular anastomotic network. ${ }^{16}$ On occasion, sacrifice of a descending branch of the superior hypophyseal artery is necessary to gain appropriate surgical access to the interval between chiasm and pituitary gland, also known as the chiasm-pituitary corridor. ${ }^{24}$ Great care is taken to preserve branches of the superior hypophyseal artery to the chiasm, which can be swept north following transection of the descending branch.

Tumor-related expansion frequently enlarges the interval between the chiasm, which is often displaced anteriorly, and the infundibular recess. ${ }^{23,24}$ In larger tumors, the inferior margin of the third ventricle is commonly displaced inferiorly, where it can be stretched to a thin translucent membrane. Access to the tumor capsule can be obtained via an incision in the thin membrane occupying the region between anteriorly displaced chiasm and stalk. Alternatively, an incision of the thinned third ventricle floor permits access to the inferior tumor capsule in select patients. The plane immediately overlying the tumor capsule is distinct from arachnoid containing eloquent neurovascular structures of the adjacent cisterns.

The tumor is internally decompressed using a combination of suction, microscissors, and the micropituitary. In larger tumors, the NICO Myriad device is used to assist with debulking. A combination of blunt and sharp extracapsular dissection is performed using ringed curettes, microscissors, and suction to dissect the tumor away from the hypothalamus. Direct visualization is key in safe dissection of the tumor from adjacent neurovascular structures. Angled endoscopes and instruments can be valuable to optimize visualization of the uppermost aspect of tumor extension. The boundary between tumor and diencephalic structures is often readily visible during the latter stages of the endonasal approach, where great care is taken in safe dissection of the tumor from the hypothalamus. While dense adherence of tumor to the lateral wall and/or hypothalamus precludes aggressive gross-total resection (GTR), this particular finding was not encountered in this series. After resection of tumor, fascia lata previously obtained from the thigh is placed over the bone defect and held in place using rigid MEDPOR (Stryker) cut appropriately to size. 10,18,19 This "gasket-seal" is covered with the nasoseptal flap, which is then buttressed with a polyethylene glycolbased hydrogel sealant. ${ }^{18,21}$ A summary of the aforementioned operative steps is presented in Fig. 1. Postoperatively, a lumbar drain is used to remove $5 \mathrm{ml}$ of CSF per hour for 48-72 hours prior to removal.

\section{Intraoperative and Postoperative Assessment}

Relevant intra- and postoperative data (e.g., surgical approach, intraoperative complications, method of closure, postoperative neurological deficit, postoperative complications, improvement in symptoms following surgery, and radiological follow-up) were assessed following surgery. The extent of tumor resection was assessed intraopera- tively using visual inspection by the senior authors and postoperatively using a neuroradiologist who reviewed the MRI. Any element of residual tumor documented in the operative note or in postoperative imaging precluded the designation of a GTR. Histology was determined based on both microscopic analysis and genotyping. The postoperative endocrine status of each patient was monitored during the patient's hospital stay and electively in the outpatient setting. The somatotrophic axis was not routinely evaluated.

Classification of postoperative visual outcomes relied on subjective patient assessment and, in some cases, formal evaluation with Humphrey visual fields. Patients with normal vision prior to surgery whose vision remained subjectively stable after surgery were classified as "normal vision maintained." In this group of patients, postoperative Humphrey visual field assessment was not routinely performed. Patients who reported new visual deterioration following surgery were classified as having "worsened" vision and were subsequently evaluated with Humphrey visual field assessment. Patients who reported compromised vision prior to surgery were routinely evaluated with preand postoperative Humphrey visual field assessment. In this group, patients whose vision did not improve postoperatively (based on subjective assessment and/or postoperative visual fields) were classified as "stable." Patients with compromised vision prior to surgery that subjectively improved following surgery were classified as "normalized" if visual fields normalized entirely. Patients who noted subjective and/or objective visual improvement in the absence of complete normalization of visual fields were designated as "improved." Tumor recurrence was monitored with MRI every 6 months for the first postoperative year followed by 1- or 2-year intervals.

\section{Results}

\section{General Cohort Characteristics}

During the period from 2006 to 2017, 80 patients underwent resection of CPAs utilizing the EEA. Of these 80 patients, $10(12.5 \%)$ were retrospectively identified to have IVCs. At time of surgery, the ages of these 10 patients ranged from 26 to 67 years with a mean age of $49.5 \pm 14.2$ years. There were 6 female $(60 \%)$ and 4 male $(40 \%)$ patients. Two of the patients had undergone biopsy prior to EEA. One patient had undergone a previous craniotomy for subtotal resection (STR) at an outside hospital. Seven patients $(70 \%)$ had preoperative endocrine abnormalities. Six patients (60\%) suffered from preoperative visual deterioration. Additional preoperative clinical and radiological characteristics can be found in Table 1. CPA size, based on preoperative MRI, ranged from 1.0 to $24.9 \mathrm{~cm}^{3}$ with a mean volume of $9.03 \pm 6.4 \mathrm{~cm}^{3}$.

Lumbar drains were placed intraoperatively in 9 of 10 surgeries to deliver intrathecal fluorescein and minimize the risk of postoperative CSF leakage. One patient that required external ventricular drain placement for obstructive hydrocephalus prior to surgery did not receive a lumbar drain prior to surgery.

Postoperative MRI with and without contrast was obtained after LD removal and used to grade extent of resec- 


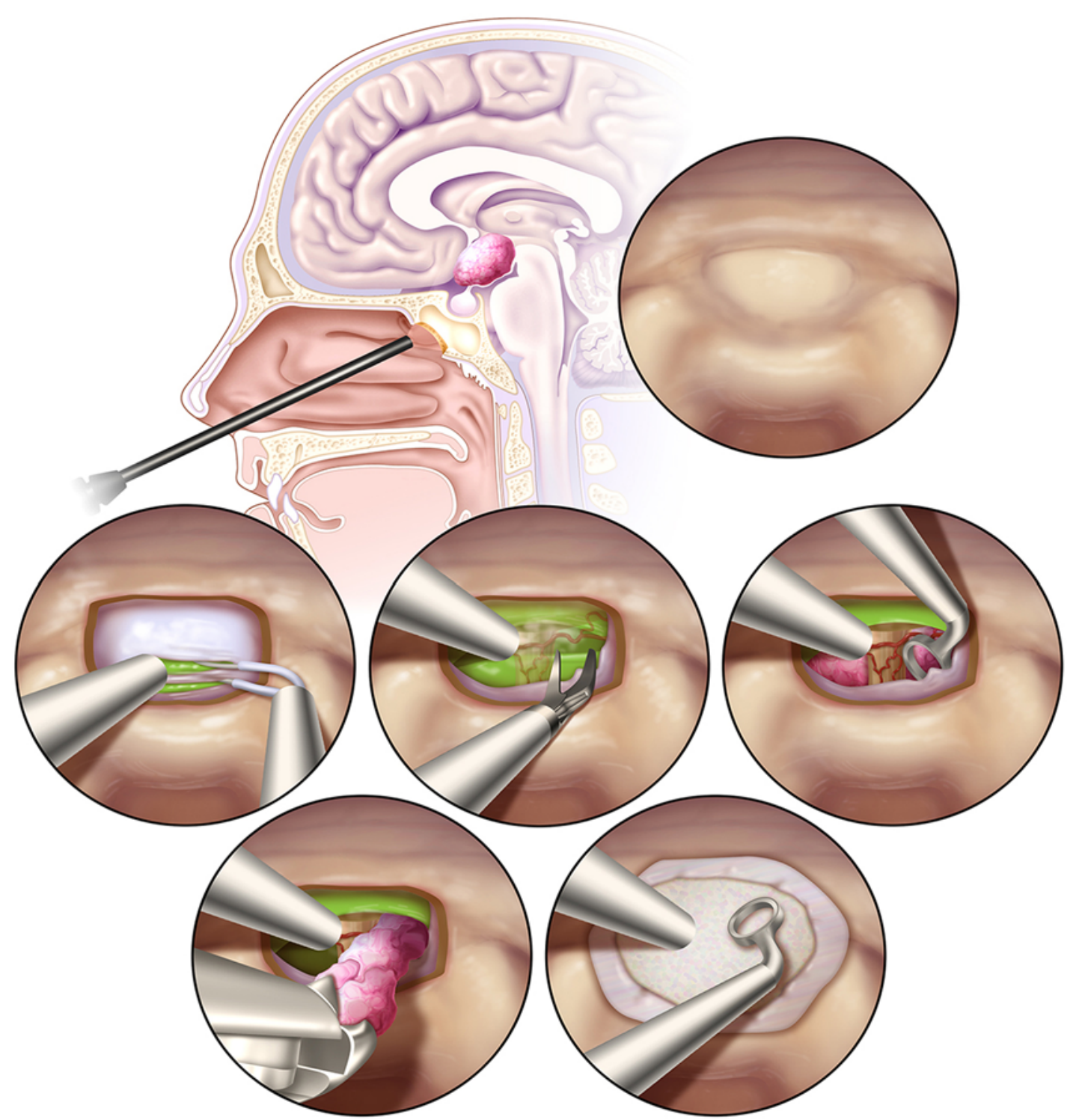

FIG. 1. Operative steps involved in resection of IVCs. Bone removal incorporates a portion of the rostral sella just below the superior intercavernous sinus and planum sphenoidale to expose the bottom of the chiasm. The superior intercavernous sinus is isolated, bipolar cauterized, and transected. Fluorescein-stained CSF clearly delineates the arachnoid space. Following sharp microdissection of the deep arachnoid, the tumor becomes visible. The tumor is internally debulked and removed using extracapsular sharp and blunt dissection. Closure proceeds using the "gasket-seal" technique. Copyright Theodore H. Schwartz. Published with permission. Figure is available in color online only.

tion. GTR, as assessed intraoperatively and with postoperative MRI, was achieved in 9 of 10 patients $(90 \%)$. The lone patient who did not undergo GTR (case 2) underwent near-total (98\%) resection (NTR) in an attempt to preserve the stalk. A small focus of residual enhancement at the level of the infundibular recess was detected on postoperative MRI. Pre- and postoperative imaging for each of the patients reported in this study can be found in Fig. 2. Additional relevant intra- and postoperative patient variables can be found in Table 2 .

\section{Endocrine and Visual Outcome}

Mean follow-up was 46.8 months (range 4-131 months). Using the criteria for visual outcome described above, the following results were obtained: in the 4 patients with normal vision prior to surgery, 3 had stable vision following tumor resection and were classified as "normal vision maintained." One patient noted the new development of an incongruous left inferior quadrantanopsia following surgery and was classified as "worsened" vision. In the 6 patients who presented with compromised vision prior to surgery, two patients did not notice any deterioration or improvement of vision postoperatively and were classified as "stable." Each of the remaining 4 patients noted significant improvement in vision following surgery. In 3 of these patients the degree of improvement was not complete-as evaluated with Humphrey visual fields. Each of these 3 patients were classified as "improved." In the final patient, 
TABLE 1. Preoperative clinical characteristics of patients who underwent endoscopic endonasal resection of CPAs

\begin{tabular}{|c|c|c|c|c|c|c|c|}
\hline \multirow{2}{*}{$\begin{array}{c}\text { Case } \\
\text { No. }\end{array}$} & \multirow{2}{*}{$\begin{array}{c}\text { Age (yrs), } \\
\text { Sex }\end{array}$} & \multicolumn{3}{|c|}{ Preop } & \multirow[b]{2}{*}{ Previous Op } & \multirow{2}{*}{$\begin{array}{c}\text { Obstructive } \\
\text { Hydrocephalus }\end{array}$} & \multirow{2}{*}{$\begin{array}{c}\text { Tumor Vo } \\
\left(\mathrm{cm}^{3}\right)\end{array}$} \\
\hline & & Symptoms & Endocrine Deficit & $\mathrm{BMI}\left(\mathrm{kg} / \mathrm{m}^{2}\right)$ & & & \\
\hline 1 & $43, F$ & VD, HP & Partial API (HG) & 32.5 & No & No & 6.16 \\
\hline 2 & $53, \mathrm{~F}$ & $\mathrm{ML}, \mathrm{HP}$ & Partial API (HG) & 49.6 & Yes (biopsy) & No & 9.76 \\
\hline 3 & $26, F$ & VD & None & 25.9 & No & No & 11.4 \\
\hline 4 & $66, F$ & $H A, V D$ & Partial API (HG*) & 24.8 & No & No & 7.7 \\
\hline 5 & $67, \mathrm{~F}$ & Dizziness & Partial API (HT, HG) & 26.9 & Yes (biopsy) & Yes & 2.9 \\
\hline 6 & $29, \mathrm{M}$ & ML, HP, VD, PS & Partial API (HG, HT, GHD) & 42.6 & No & No & 24.9 \\
\hline 7 & $51, \mathrm{M}$ & VD, HA, ML & None & 22.7 & No & No & 10.1 \\
\hline 8 & $55, \mathrm{M}$ & HA (recurrence) & DI & 27.3 & Yes (craniotomy, STR) & No & 1.0 \\
\hline 9 & $44, \mathrm{M}$ & $\mathrm{VD}, \mathrm{HA}$ & None & 24.4 & No & No & 6.3 \\
\hline 10 & $61, F$ & $\mathrm{HA}, \mathrm{Sz}$ & $\mathrm{DI}$ & 31 & No & Yes & 10.1 \\
\hline
\end{tabular}

$\mathrm{API}=$ anterior pituitary insufficiency; $\mathrm{DI}=$ diabetes insipidus; $\mathrm{GHD}=$ growth hormone deficiency; $\mathrm{HA}=$ headache; $\mathrm{HG}=$ hypogonadism; $\mathrm{HP}=$ hyperphagia; $\mathrm{HT}=$ hypothyroidism; $\mathrm{ML}=$ memory loss; $\mathrm{PS}=$ psychiatric; $\mathrm{Sz}=$ seizure; $\mathrm{VD}=$ visual deterioration.

* While adrenal insufficiency was excluded, the remaining hypothalamic-pituitary axis was not comprehensively assessed prior to surgery.

formal Humphrey visual field assessment demonstrated vision had recovered completely following surgery. This patient was classified as "normalized." Overall, vision remained stable or improved in $90 \%$ of patients following surgery (Table 2). Seven patients $(70 \%)$ developed panhypopituitarism postoperatively. Two additional patients (20\%) developed progression to complete anterior pituitary insufficiency without associated diabetes insipidus. Additional information regarding specific components of postoperative endocrine dysfunction for each individual patient can be found in Table 2. Of note, 7 patients (70\%) in this series had suffered from some element of pituitary insufficiency prior to surgery (Table 1).

\section{Additional Complications}

Additional postoperative complications can be found in Table 2. One patient (case 6, illustrative case below) with a BMI of $42.6 \mathrm{~kg} / \mathrm{m}^{2}$ suffered abrupt onset of CSF rhinorrhea following a coughing episode on postoperative day 6 that required a return to the operating room for revision of closure with lumbar drain placement. Aside from the single case of postoperative visual deterioration discussed above, no patients suffered any form of neurological deterioration following surgery. Preoperative BMIs are recorded in Table 1 and postoperative BMIs can be found in Table 2. One patient's BMI (case 3) was noted to have increased from $25.9 \mathrm{~kg} / \mathrm{m}^{2}$ prior to surgery to $42.9 \mathrm{~kg} / \mathrm{m}^{2}$ approximately 6 years following surgery-likely consistent with the new development of hypothalamic obesity. In all other patients the difference between pre- and postoperative BMI was less than 7.

\section{Adjuvant Therapy and Recurrence}

One patient (case 2) who underwent NTR was treated with radiation therapy (XRT) for the small focus of residual tumor following surgery; subsequent MRI has been negative for evidence of interval growth. In a separate patient (case 3) who originally underwent GTR, a small focus of tumor recurrence developed in the interpeduncular cistern 42 months following the initial surgery. This was treated with fractionated XRT. Following XRT, subsequent MRI has likewise been negative for evidence of tumor recurrence. Another patient (case 10) was found to have tumor recurrence involving the infundibular recess 20 months following surgery. As the pathology for this tumor was papillary CPA with known BRAF (V600E) mutation, the decision was made to initiate a trial of BRAF/ MEK inhibitor in lieu of postoperative XRT.

\section{Illustrative Case}

A 29 -year-old, morbidly obese (BMI $42.6 \mathrm{~kg} / \mathrm{m}^{2}$ ) man initially presented with depression, memory loss, personality changes, and visual deterioration. Subsequent MRI demonstrated a $4.2-\mathrm{cm}$ heterogeneously enhancing lesion occupying the confines of the third ventricle (Fig. 2, case 6). CT demonstrated peripheral calcification of the lesion. Examination was notable for decreased attention span and bitemporal hemanopsia. Laboratory assessment prior to surgery demonstrated evidence of hypogonadism, hypothyroidism, and growth hormone deficiency. Hormonal replacement with levothyroxine was initiated. Dedicated visual field assessment confirmed a bitemporal defect. The decision was made to proceed with an EEA for resection (Fig. 3; Video 1).

VIDEO 1. Edited and narrated intraoperative video demonstrating endonasal resection of an IVC (case 6). Copyright Jonathan Forbes. Published with permission. Click here to view.

Following surgery, the patient was maintained on hydrocortisone and desmopressin and extubated the following morning. His neurological examination at this time was grossly unchanged in comparison to his preoperative examination. Postoperative MRI demonstrated GTR of the neoplasm (Fig. 2, case 6). The lumbar drain was discontinued the morning of postoperative day 3. After a coughing fit on postoperative day 6, CSF rhinorrhea was noted. The patient was subsequently returned to the operating room, where a lumbar drain was replaced. After the nasoseptal flap was taken down, CSF could be seen leaking from the rostral aspect of the gasket seal where it had been dislodged from the sudden massive increase in 
Forbes et al.

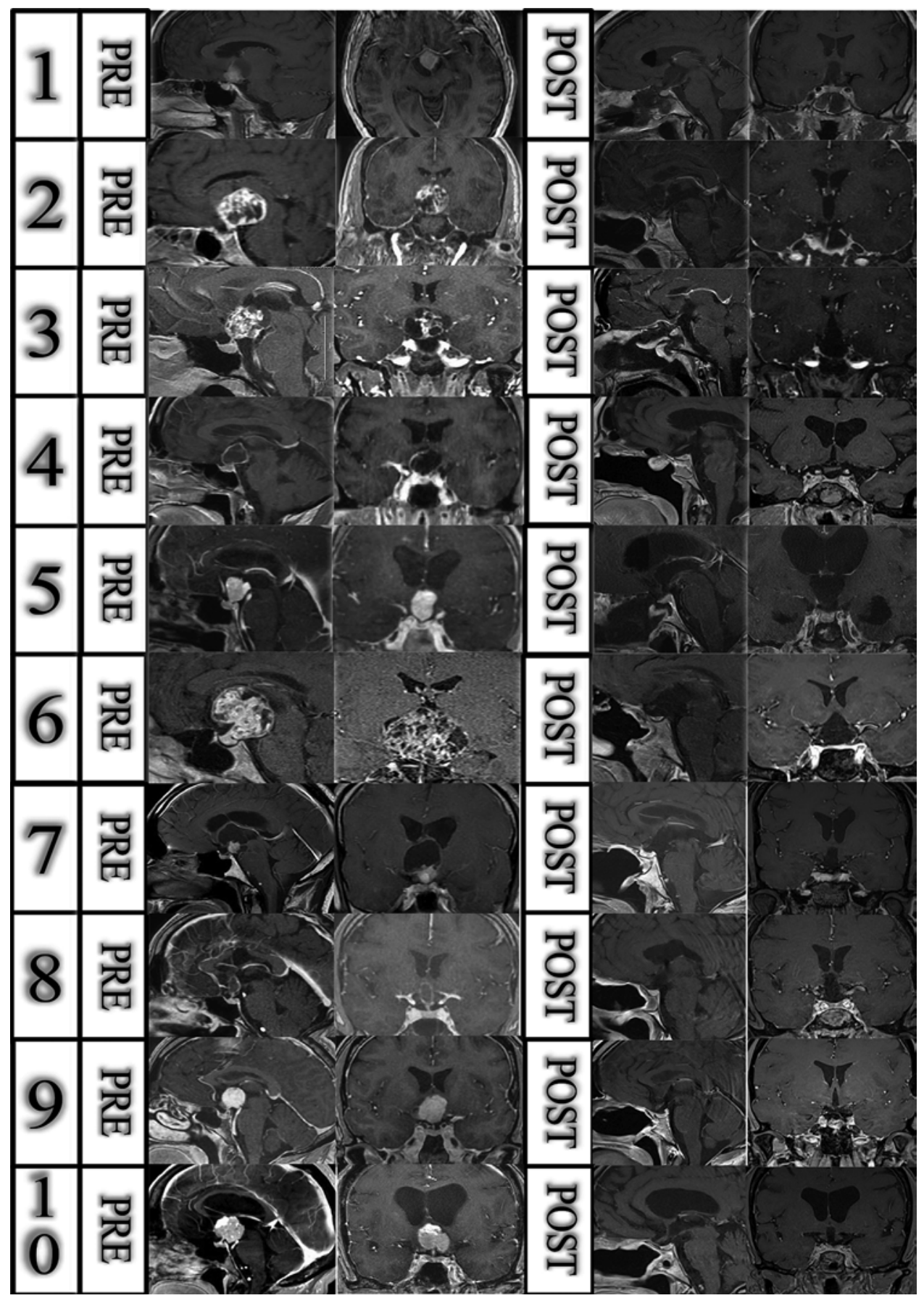

FIG. 2. Pre- and postoperative T1-weighted postcontrast MRI imaging of cases 1-10.

intracranial pressure. The MEDPOR was removed and the gasket-seal closure was revised. The nasoseptal flap was replaced and buttressed with DuraSeal and a Foley balloon catheter. The patient was treated with a prolonged course of lumbar drainage prior to uneventful discharge home. After discharge, he returned to the emergency department 3 days later with a low-grade fever. Workup during the subsequent hospitalization, including blood and CSF cultures, remained negative. Repeat endoscopy at this time confirmed appropriate healing of the closure without evi- dence of CSF leakage and the patient was again discharged home. Subsequent follow-up in the outpatient clinic has demonstrated marked objective improvement in preoperative bitemporal hemianopsia with considerable subjective improvement in memory impairment and personality.

\section{Discussion}

Intraventricular CPAs are infrequently encountered and commonly misclassified. Pascual et al. separated 130 
TABLE 2. Intra- and postoperative clinical characteristics of patients who underwent endoscopic endonasal resection of only IVCs

\begin{tabular}{|c|c|c|c|c|c|c|c|c|c|c|}
\hline $\begin{array}{l}\text { Case } \\
\text { No. }\end{array}$ & $\begin{array}{l}\text { Extent of } \\
\text { Resection }\end{array}$ & Stalk & $\begin{array}{c}\text { Visual } \\
\text { Outcome }\end{array}$ & Postop Endocrine Deficit & Postop Complications & Pathol & $\begin{array}{c}\text { FU } \\
\text { (mos) }\end{array}$ & $\begin{array}{c}\text { Postop BMI } \\
\left(\mathrm{kg} / \mathrm{m}^{2}\right)\end{array}$ & $\begin{array}{c}\text { Tumor } \\
\text { Recurrence }\end{array}$ & $\begin{array}{c}\text { Postop } \\
\text { XRT }\end{array}$ \\
\hline 1 & GTR & $P$ & ST & Partial API (HT, HG) & None & $A D$ & 131 & 33.7 & No & No \\
\hline 2 & NTR $(98 \%)$ & $P$ & NVM & Complete API* (HT, HG, HC) & None & $A D$ & 78 & 53.9 & No & Yes \\
\hline 3 & GTR & $P$ & VN & $\mathrm{PHP}^{*}$ (complete API + DI) & Recurrent sinusitis & $A D$ & 75 & 42.9 & Yes & Yes \\
\hline 4 & GTR & $T$ & $\mathrm{VI}$ & $\mathrm{PHP}^{*}$ (complete API + DI) & None & $A D$ & 67 & 31.6 & No & No \\
\hline 5 & GTR & $T$ & NVM & $\mathrm{PHP}^{*}$ (complete API + DI) & None & PAP & 16 & 27.0 & No & No \\
\hline 6 & GTR & $\mathrm{T}$ & VI & $\mathrm{PHP}^{*}$ (complete API + DI) & CSF leakage, FUO & $A D$ & 4 & 42.3 & No & No \\
\hline 7 & GTR & $T$ & $\mathrm{VI}$ & $\mathrm{PHP}^{*}$ (complete API + DI) & None & $A D$ & 46 & 23.6 & No & No \\
\hline 8 & GTR & $P$ & VW & $\mathrm{PHP}^{*}$ (complete API + DI) & New incongruous LIQ & $A D$ & 13 & 32.55 & No & No \\
\hline 9 & GTR & $T$ & ST & Complete API (HT, HG, HC) & None & PAP & 5 & 23.3 & No & No \\
\hline 10 & GTR & $\mathrm{T}$ & NVM & $\mathrm{PHP}^{*}$ (complete API + DI) & None & PAP & 33 & 28.7 & Yes & No \\
\hline
\end{tabular}

$\mathrm{AD}=$ adamantinomatous; $\mathrm{FU}=$ follow-up; FUO = fever of unknown origin; $\mathrm{HC}=$ hypocortisolism; $\mathrm{LIQ}=$ left inferior quadrantanopsia; $\mathrm{NVM}=$ normal vision maintained; $\mathrm{P}$ = preserved; $\mathrm{PAP}=$ papillary; Pathol = pathology; $\mathrm{PHP}=$ panhypopituitarism (complete $\mathrm{API}$ and DI); $\mathrm{ST}=$ vision stable; $\mathrm{T}=$ transected; $\mathrm{VI}=$ vision improved; $\mathrm{VN}=$ vision normalized; $\mathrm{VW}=$ vision worsened.

Cases 2-10 had new endocrine deficits.

* Growth hormone stimulation test for confirmation of growth hormone deficiency was not performed.

CPAs previously described as intraventricular in various publications into the following 4 subcategories: 1) strictly intraventricular, 2) not strictly intraventricular (infundibulotuberal), 3) secondarily intraventricular (extraintraventricular), and 4) pseudointraventricular (suprasellar third ventricle, invaginating). ${ }^{25}$ Following retrospective analysis of this group of 130 CPAs, the authors recategorized 31 tumors $(24.6 \%)$ as "strictly-intraventricular," $51(39.2 \%)$ as "not strictly intraventricular," $30(23.1 \%)$ as "secondarily intraventricular," and 18 (13.8\%) as "pseudointraventricular." This work called attention to the morphological heterogeneity of CPAs placed under the larger umbrella of the "intraventricular" designation; the finding that 48 tumors (36.9\%) were either "secondarily intraventricular" or "pseudointraventricular" was especially notable. Of interest, the authors felt the second category of infundibulotuberal CPAs (specifically the adamantinomatous pathology) was associated with the highest surgical risk due to frequent difficulty in identifying and following a nontraumatic plane of dissection at the margin of normal hypothalamus and peritumoral gliosis. ${ }^{25}$ In categorizing the tumors in this paper, tumors limited to the confines of the third ventricle (i.e., Kassam type IV tumors) that satisfied the Pascual criteria of "strictly intraventricular" and "infundibulotuberal" were denoted as IVC and selected for study inclusion.

Although many authors have moved toward the EEA for resection of the majority of CPAs, the literature is fairly consistent in recommending against the EEA for the subset of IVCs. In 1990, Yaşargil et al. referenced purely intraventricular CPAs as "lying within the third ventricle." In this study, he recommended that transsphenoidal approaches be limited to intrasellar-infradiaphragmatic CPAs and voiced preference for transcallosal resection of intraventricular CPAs. ${ }^{32}$ In a landmark 2008 publication describing advances in the ability to resect pre-, trans-, and retro-infundibular tumors using the EEA, Kassam et al. recommended against the use of the EEA for resection of intraventricular (Kassam type IV) tumors, described as "isolated to the third ventricle and/or optic recess."13 In 2010, Yamada et al. voiced solidarity with this opinion, but did not address specific anatomical measures of inclusion regarding the intraventricular designation. ${ }^{31}$ In 2013, Koutourousiou et al. differentiated between CPAs with pure third ventricle involvement and those that extended to involve the third ventricle. While the rate of GTR of CPAs with intraventricular extension was higher (42.9\%) than for extraventricular CPAs (34.0\%), the authors were resolute in stating that endonasal approaches had been chosen for the treatment of every CPA at their institution for the past 12 years with the exception of the purely intraventricular variety. ${ }^{16}$ From 2004 to the present, it has been the senior author's preference to resect all CPAs, including IVCs, using an endoscopic endonasal corridor. In light of the controversy surrounding operative management of IVCs, this study was undertaken to evaluate the safety and efficacy of the expanded endonasal approach in addressing this rare subset of CPAs.

\section{Traditional Microsurgical Approaches}

Traditionally, CPAs limited to the confines of the third ventricle have been resected using open, microsurgical approaches that include the translamina terminalis and transventricular (i.e., transcortical or transcallosal) corridors. ${ }^{28}$ Many authors have recommended use of tumor morphology to guide the surgical approach. Strategies recommending the use of a transventricular approach for larger tumors and tumors that favor the posterosuperior aspect of the third ventricle, and the translamina terminalis approach for tumors occupying the anteroinferior portion of the third ventricle, have been advocated. ${ }^{15,28,33}$ The use of both approaches in a staged manner for large IVC has also been described. ${ }^{9}$ The clinical results obtained in dedicated series of purely IVCs treated with open microsurgical resection have been variable and reflect the challenging nature of the complicated subset of tumors (Table 3). Rates of GTR have ranged from $50 \%$ to $100 \%$ with significant, associat- 

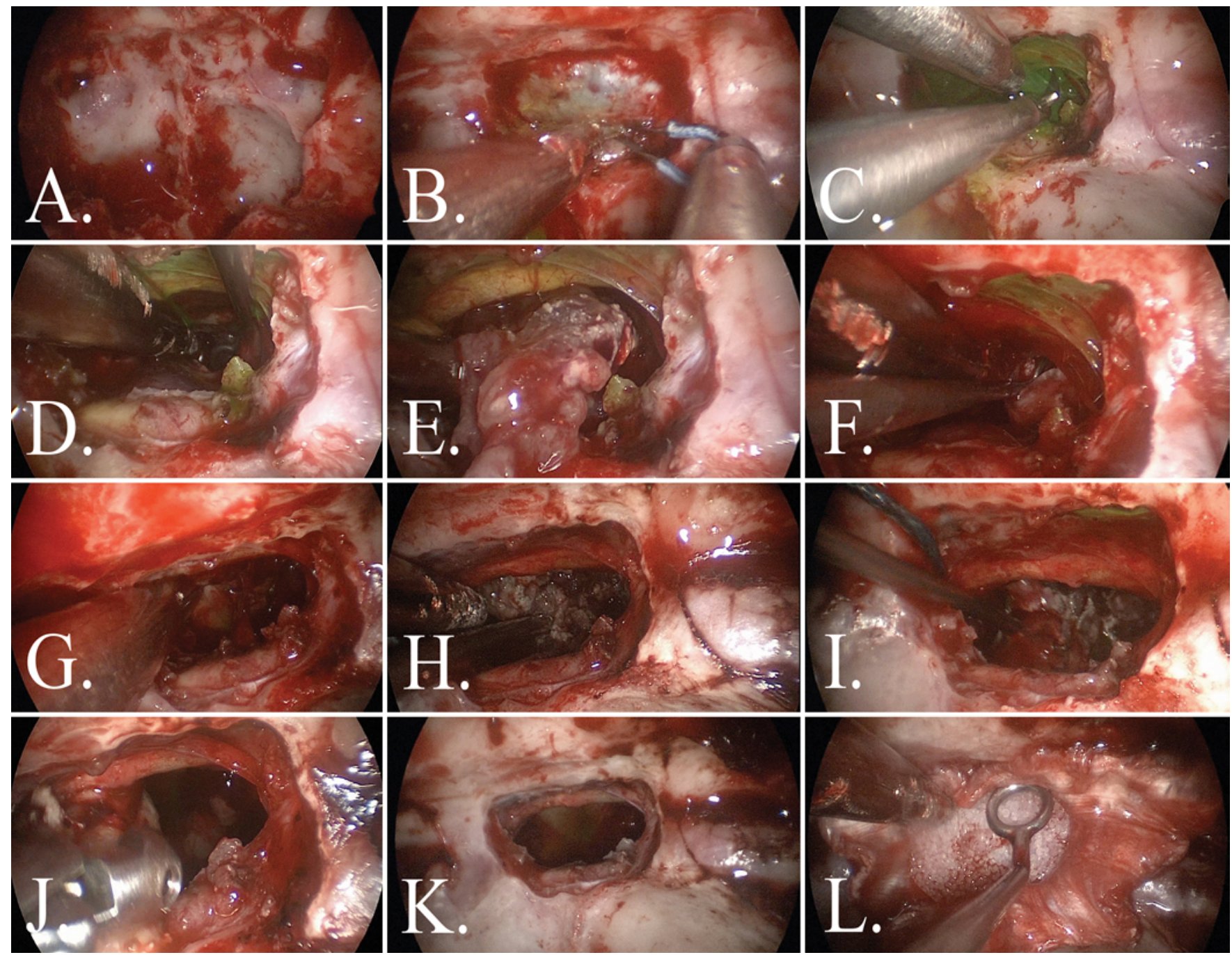

FIG. 3. Case 6. A: Endoscopic endonasal view of the sella prior to bone removal. B: Isolated superior intercavernous sinus is cauterized prior to transection. C: Underlying arachnoid of the suprasellar cistern is sharply entered using microscissors. Fluoresceinstained CSF is apparent. D: The inferior margin of the tumor capsule is mobilized using a ringed curette. E and F: Following intratumoral mobilization, piecemeal debulking proceeds using micropituitary instrumentation and ringed curettes. G: The pituitary stalk, visualized here, later required transection to achieve GTR. H-J: The last fragment of tumor is delivered inferiorly from the posterior aspect of the optic chiasm $(\mathrm{H})$, where it can be debulked under direct visualization using the NICO Myriad device (I) prior to final removal $(\mathrm{J})$. K and $\mathrm{L}$ : The bone and dural defects visible following GTR of the tumor $(\mathrm{K})$ are closed using the gasket-seal technique (L). Figure is available in color online only.

ed postoperative neurological impairment in $0 \%-33 \%$ and new endocrinological deficit in $25 \%-62.5 \%$ of the index population.

While the aforementioned open microsurgical approaches remain necessary components in the armamentarium of the treating neurosurgeon, each is associated with drawbacks that merit additional discussion. Entry through the lamina terminalis is associated with risks to the adjacent optic pathways, supraoptic nuclei of the hypothalamus, and columns of the fornix. The small translamina terminalis corridor is biased toward the inferior aspect of the third ventricle. ${ }^{20}$ When approached from an anterolateral vantage, as with a pterional corridor, dissection of the margin between tumor and ipsilateral hypothalamus sometimes proceeds with limited visualization. While the problem of decreased ipsilateral visualization can be alleviated to some extent with incorporation of a midline subfrontal interhemispheric approach, visualization of the superior extent of tumor extension often remains suboptimal. ${ }^{28}$ Incorporation of the subfrontal approach requires additional dissection of the olfactory bulb/tracts and necessitates management of frontal sinus transgression. The limitations associated with transventricular routes are quite different from those associated with the translamina terminalis approach. In this route, surgical entry in the ventricles is achieved via transcortical or transcallosal corridors. In the absence of a dilated ventricular system, access to the third ventricle must proceed via enlargement of the foramen of Monro, which is associated with some element of risk to the ipsilateral fornix and deep venous structures. 
TABLE 3. Previous studies reporting series of open, microsurgical resection of only IVCs in the literature after 2000

\begin{tabular}{|c|c|c|c|c|c|c|c|c|c|}
\hline Authors \& Year & $\begin{array}{l}\text { No. of } \\
\text { Pts }\end{array}$ & $\begin{array}{c}\text { Approach } \\
\text { (TC/TLT/TC-TV) }\end{array}$ & GTR & New Endocrine Morbidity & $\begin{array}{c}\text { Other } \\
\text { Morbidity }\end{array}$ & TR & $\begin{array}{c}\text { Mean FU } \\
\text { (mos) }\end{array}$ & $\begin{array}{l}\text { Postop } \\
\text { XRT }\end{array}$ & $\begin{array}{l}\text { Pts Alive } \\
\text { at Last FU }\end{array}$ \\
\hline Yu et al., 2014 & 24 & $15 / 7 / 2$ & $19(79 \%)^{*}$ & API: 13 (54\%),† DI: 15 (62.5\%) & SPNI: $5(21 \%)$ & 6 & 42 & 4 & $19(79 \%)$ \\
\hline Jung et al., 2012 & 4 & $4 / 0 / 0$ & $4(100 \%)$ & PHP: 2 (50\%) & NR & 2 & 59 & $1 \ddagger$ & $4(100 \%)$ \\
\hline Behari et al., 2003 & 6 & $3 / 3 / 0$ & $3(50 \%)$ & API: 2 (33\%), DI: 1 (17\%) & VPS: $1(17 \%)$ & 0 & 20 & 2 & $5(83 \%)$ \\
\hline Maira et al., 2004 & 8 & $0 / 8 / 0$ & $7(88 \%)$ & PHP: $2(25 \%)$ & SPNI: $2(25 \%)$ & NS & 117 & NS & $6(75 \%)$ \\
\hline
\end{tabular}

NR = none reported; NS = not specified; Pts = patients; SPNI = significant postoperative neurological impairment; TC = transcallosal; TC-TV = TC-transventricular; TLT

= translamina terminalis; TR = tumor recurrence; VPS = ventriculoperitoneal shunt.

* GTR in this study was defined as removal of $>95 \%$ of the tumor.

$\dagger$ Yu et al. cited the following values for new postoperative anterior pituitary insufficiency: corticotroph insufficiency 13 (54\%), panhypopituitarism 8 (33\%).

$\ddagger$ One patient lost to follow-up after recurrence detected.

Additionally, the working depth in the transventricular approaches is considerable, which can complicate efforts at dissection of the deep margin of the tumor from eloquent neurovascular structures when adherence is present.

\section{EEA for Resection of IVCs}

The benefits of the EEA include direct access to ventral midline structures with minimal associated neurovascular manipulation and/or retraction. Additionally, the ability to deliver the endoscopic camera and light source to the region of tumor involvement allows for enhanced visualization of the tumor-hypothalamic interface. Previous studies have noted superior results in patients with CPAs and visual compromise treated using the EEA. ${ }^{14,19,22}$ Drawbacks associated with the EEA in this setting include the learning curve associated with the use of long-shaft instruments in an endonasal setting as well as an increased risk of postoperative CSF fistula..$^{14,22}$

Until recently, resection of CPAs limited to the confines of the third ventricle utilizing a purely EEA had not been reported. However, over the past few years, a small number of patients with IVCs treated with EEA for resection have been described (Table 4). ${ }^{3,11,23}$ The 10 patients described in this report represent the largest number of patients to date with IVCs treated using the EEA for resection. Commensurate with the previous studies summarized in Table 4 the rates of GTR and postoperative neurological morbidity in this study compare favorably to historical standards. The relatively high incidence of postoperative endocrinologi- cal morbidity in this study, as well as the previous report by Nishioka et al., is likely reflective to some extent of the high rates of GTR that have been achieved ${ }^{23}$ Consistent with previous studies evaluating use of the EEA for resection of CPAs, the incidence of CSF fistula following the EEA for resection of IVCs in this series was slightly higher than what has previously been reported in series employing open microsurgical techniques. ${ }^{16,19}$ Additional investigation is necessary; however, increased risks of endocrine insufficiency and postoperative CSF fistula following the EEA appear to be justified by increased rates of GTR and decreased rates of significant postoperative neurological morbidity when compared to traditional, open approaches. Collectively, the authors believe the data presented in this study demonstrates that the EEA for resection of IVCs is a safe and efficacious operative strategy that should be considered a surgical option in treatment of this challenging subset of tumors.

\section{Limitations}

This study is limited by its inherent retrospective nature, which requires reliance on the accuracy of clinical records in addition to methodological heterogeneity in visual assessment. Patients without subjective visual complaints before and after surgery were not routinely assessed with formal Humphrey visual field examination. Additionally, the time course associated with attainment of visual fields was not standardized. The sensitivity of the aforementioned protocol, with regards to detection of visual deterioration,

TABLE 4. Previous studies reporting patients treated with the EEA for resection of IVCs

\begin{tabular}{|c|c|c|c|c|c|c|c|c|}
\hline Authors \& Year & $\begin{array}{l}\text { No. of } \\
\text { Pts }\end{array}$ & $\begin{array}{l}\text { GTR } \\
(\%)\end{array}$ & $\begin{array}{l}\text { New Endocrine Morbidity } \\
(\%)\end{array}$ & $\begin{array}{l}\text { Other Morbidity } \\
\text { (cases) }\end{array}$ & $\operatorname{TR}(\%)$ & $\begin{array}{c}\text { Mean FU } \\
\text { (mos) }\end{array}$ & $\begin{array}{l}\text { Postop } \\
\text { XRT (\%) }\end{array}$ & $\begin{array}{l}\text { Pts Alive at } \\
\text { Last FU (\%) }\end{array}$ \\
\hline Nishioka et al., 2016 & 3 & $3(100)$ & PHP: 3 (100) & None & 0 & 18 & 0 & $3(100)$ \\
\hline Gu et al., 2015 & 3 & $3(100)$ & API: 0 (0), ${ }^{*}$ DI: $0(0)^{*}$ & VD (1), CSF leak (1)† & $1(33)$ & 36 & $1(33)$ & $3(100)$ \\
\hline Cavallo et al., 2014 & 1 & $1(100)$ & NS & CSF leak (1) & NS & 63 & 0 & $1(100)$ \\
\hline Current study & 10 & $9(90)$ & $\begin{array}{l}\text { PHP: } 7 \text { (70); progression to } \\
\text { complete API: } 9 \text { (90) }\end{array}$ & CSF leak (1), VD (1) & $2(20)$ & 47 & $2(20)$ & $10(100)$ \\
\hline
\end{tabular}

\footnotetext{
* All patients had some element of API prior to surgery, but pituitary function did not worsen following surgery.

$\dagger$ Patient required ventriculoperitoneal shunt insertion.
} 
is potentially lower than would be expected for a protocol that employed universal formal visual field examination before and after surgery at standardized intervals.

\section{Conclusions}

The 10 patients described in this report represent the largest number of patients with IVC treated using the EEA for resection to date. Results indicate that the EEA for resection of IVCs is a safe and efficacious operative strategy that should be considered a surgical option for treatment of this challenging subset of tumors.

\section{References}

1. Al-Mefty O, Ayoubi S, Kadri PA: The petrosal approach for the total removal of giant retrochiasmatic craniopharyngiomas in children. J Neurosurg 106 (2 Suppl):87-92, 2007

2. Behari S, Banerji D, Mishra A, Sharma S, Sharma S, Chhabra DK, et al: Intrinsic third ventricular craniopharyngiomas: report on six cases and a review of the literature. Surg Neurol 60:245-253, 2003

3. Cavallo LM, Frank G, Cappabianca P, Solari D, Mazzatenta D, Villa A, et al: The endoscopic endonasal approach for the management of craniopharyngiomas: a series of 103 patients. J Neurosurg 121:100-113, 2014

4. Cavallo LM, Prevedello DM, Solari D, Gardner PA, Esposito F, Snyderman CH, et al: Extended endoscopic endonasal transsphenoidal approach for residual or recurrent craniopharyngiomas. J Neurosurg 111:578-589, 2009

5. Conger AR, Lucas J, Zada G, Schwartz TH, Cohen-Gadol AA: Endoscopic extended transsphenoidal resection of craniopharyngiomas: nuances of neurosurgical technique. Neurosurg Focus 37(4):E10, 2014

6. Couldwell WT, Weiss MH, Rabb C, Liu JK, Apfelbaum RI, Fukushima T: Variations on the standard transsphenoidal approach to the sellar region, with emphasis on the extended approaches and parasellar approaches: surgical experience in 105 cases. Neurosurgery 55:539-550, 2004

7. Dhandapani S, Singh H, Negm HM, Cohen S, Souweidane $\mathrm{MM}$, Greenfield JP, et al: Endonasal endoscopic reoperation for residual or recurrent craniopharyngiomas. J Neurosurg 126:418-430, 2017

8. Frank G, Pasquini E, Doglietto F, Mazzatenta D, Sciarretta V, Farneti G, et al: The endoscopic extended transsphenoidal approach for craniopharyngiomas. Neurosurgery 59 (1 Suppl):ONS75-ONS83, 2006

9. Fukushima T, Hirakawa K, Kimura M, Tomonaga M: Intraventricular craniopharyngioma: its characteristics in magnetic resonance imaging and successful total removal. Surg Neurol 33:22-27, 1990

10. Garcia-Navarro V, Anand VK, Schwartz TH: Gasket seal closure for extended endonasal endoscopic skull base surgery: efficacy in a large case series. World Neurosurg 80:563-568, 2013

11. Gu Y, Zhang X, Hu F, Yu Y, Xie T, Sun C, et al: Suprachiasmatic translamina terminalis corridor used in endoscopic endonasal approach for resecting third ventricular craniopharyngioma. J Neurosurg 122:1166-1172, 2015

12. Jung TY, Jung S, Jang WY, Moon KS, Kim IY, Kang SS: Operative outcomes and adjuvant treatment of purely third ventricle craniopharyngioma after a transcallosal approach. Br J Neurosurg 26:355-360, 2012

13. Kassam AB, Gardner PA, Snyderman CH, Carrau RL, Mintz AH, Prevedello DM: Expanded endonasal approach, a fully endoscopic transnasal approach for the resection of midline suprasellar craniopharyngiomas: a new classification based on the infundibulum. J Neurosurg 108:715-728, 2008
14. Komotar RJ, Starke RM, Raper DM, Anand VK, Schwartz TH: Endoscopic endonasal compared with microscopic transsphenoidal and open transcranial resection of craniopharyngiomas. World Neurosurg 77:329-341, 2012

15. Konovalov AN: Third ventricle craniopharyngiomas. World Neurosurg 82:1023-1025, 2014

16. Koutourousiou M, Gardner PA, Fernandez-Miranda JC, Tyler-Kabara EC, Wang EW, Snyderman CH: Endoscopic endonasal surgery for craniopharyngiomas: surgical outcome in 64 patients. J Neurosurg 119:1194-1207, 2013

17. Koutourousiou M, Vaz Guimaraes Filho F, Fernandez-Miranda JC, Wang EW, Stefko ST, Snyderman CH, et al: Endoscopic endonasal surgery for tumors of the cavernous sinus: a series of 234 patients. World Neurosurg 103:713-732, 2017

18. Leng LZ, Brown S, Anand VK, Schwartz TH: "Gasket-seal" watertight closure in minimal-access endoscopic cranial base surgery. Neurosurgery 62 (5 Suppl 2):ONSE342-ONSE343, 2008

19. Leng LZ, Greenfield JP, Souweidane MM, Anand VK, Schwartz TH: Endoscopic, endonasal resection of craniopharyngiomas: analysis of outcome including extent of resection, cerebrospinal fluid leak, return to preoperative productivity, and body mass index. Neurosurgery 70:110-124, 2012

20. Maira G, Anile C, Albanese A, Cabezas D, Pardi F, Vignati A: The role of transsphenoidal surgery in the treatment of craniopharyngiomas. J Neurosurg 100:445-451, 2004

21. McCoul ED, Anand VK, Singh A, Nyquist GG, Schaberg MR, Schwartz TH: Long-term effectiveness of a reconstructive protocol using the nasoseptal flap after endoscopic skull base surgery. World Neurosurg 81:136-143, 2014

22. Moussazadeh N, Prabhu V, Bander ED, Cusic RC, Tsiouris AJ, Anand VK, et al: Endoscopic endonasal versus open transcranial resection of craniopharyngiomas: a casematched single-institution analysis. Neurosurg Focus 41(6):E7, 2016

23. Nishioka H, Fukuhara N, Yamaguchi-Okada M, Yamada S: Endoscopic endonasal surgery for purely intrathird ventricle craniopharyngioma. World Neurosurg 91:266-271, 2016

24. Omay SB, Almeida JP, Chen YN, Shetty SR, Liang B, Ni $\mathrm{S}$, et al: Is the chiasm-pituitary corridor size important for achieving gross-total resection during endonasal endoscopic resection of craniopharyngiomas? J Neurosurg [epub ahead of print November 24, 2017; DOI: 10.3171/2017.6.JNS163188]

25. Pascual JM, Prieto R, Carrasco R, Barrios L: Displacement of mammillary bodies by craniopharyngiomas involving the third ventricle: surgical-MRI correlation and use in topographical diagnosis. J Neurosurg 119:381-405, 2013

26. Placantonakis DG, Tabaee A, Anand VK, Hiltzik D, Schwartz TH: Safety of low-dose intrathecal fluorescein in endoscopic cranial base surgery. Neurosurgery 61 (3 Suppl):161-166, 2007

27. Prabhu V, Anand VK, Schwartz TH: Preservation of pituitary function after endonasal craniopharyngioma surgery: case report and review of the literature. Cureus 7:e305, 2015

28. Quiñones-Hinojosa A (ed): Schmidek and Sweet: Operative Neurosurgical Techniques, ed 6. Philadelphia: Saunders Elsevier, 2012

29. Samii M, Tatagiba M: Surgical management of craniopharyngiomas: a review. Neurol Med Chir (Tokyo) 37:141-149, 1997

30. Steno J, Malácek M, Bízik I: Tumor-third ventricular relationships in supradiaphragmatic craniopharyngiomas: correlation of morphological, magnetic resonance imaging, and operative findings. Neurosurgery 54:1051-1060, 2004

31. Yamada S, Fukuhara N, Oyama K, Takeshita A, Takeuchi Y, Ito J, et al: Surgical outcome in 90 patients with craniopharyngioma: an evaluation of transsphenoidal surgery. World Neurosurg 74:320-330, 2010

32. Yaşargil MG, Curcic M, Kis M, Siegenthaler G, Teddy PJ, 
Roth P: Total removal of craniopharyngiomas. Approaches and long-term results in 144 patients. J Neurosurg 73:3-11, 1990

33. Yu T, Sun X, Ren X, Cui X, Wang J, Lin S: Intraventricular craniopharyngiomas: surgical management and outcome analyses in 24 cases. World Neurosurg 82:1209-1215, 2014

\section{Disclosures}

Dr. Schwartz reports owning stock options with Visionsense and being a consultant for Elliquence.

\section{Author Contributions}

Conception and design: all authors. Acquisition of data: Forbes, Ordóñez-Rubiano, Banu, Younus, Phillips. Analysis and interpretation of data: Schwartz, Forbes, Tomasiewicz, Banu, Dobri, Phil- lips, Kacker, Cisse, Anand. Drafting the article: Schwartz, Forbes, Tomasiewicz, Dobri. Critically revising the article: Schwartz, Forbes, Ordóñez-Rubiano, Tomasiewicz, Banu, Younus, Dobri, Kacker, Cisse, Anand. Reviewed submitted version of manuscript: Schwartz, Forbes, Ordóñez-Rubiano, Tomasiewicz, Banu, Younus, Dobri, Kacker, Cisse, Anand. Approved the final version of the manuscript on behalf of all authors: Schwartz. Study supervision: Schwartz.

\section{Supplemental Information \\ Videos}

Video 1. https://vimeo.com/281972742.

\section{Correspondence}

Theodore H. Schwartz: Weill Cornell Medical College, New York, NY.schwarh@med.cornell.edu. 